\title{
Zoological Tracking System with Portable Power using Sensors and Fuel Cell System
}

\author{
Ranjani Rajagopal \\ Assistant Professor \\ Vivekanandha College of \\ Engineering For Women, \\ Tiruchengode, Namakkal, \\ India -637 205
}

\author{
Dilip Kumar. M \\ Assistant Professor \\ Vivekanandha College Of \\ Engineering For Women, \\ Tiruchengode, Namakkal, \\ India -637 205
}

\author{
Mutharasu.M \\ Assistant Professor \\ Vivekanandha College Of \\ Engineering For Women, \\ Tiruchengode, Namakkal, \\ India -637205
}

\begin{abstract}
We propose a highly efficient active DMFC system for tracking application. With this technology of active DMFC system tracking of animals in forest area has been achieved to a great extent. The system is composed of charging module, a smart battery and tracking unit. The charging module consists of fuel cell stack, mechanical part and circuit parts. Mechanical part for injection speed of pure methanol, temperature control because high fuel efficiency is essential for portable application. Circuit part consists of two synchronous buck-boost converters, first one charges the battery and supplies the power to the second stage converter, second one regulates the output voltage. The tracking unit consists of the GPS, Sensor and controlling circuit. Our existing systems just sense and provide the result to the base station. In proposed system it sense the parameter via sensor nodes and transmits to base station. The control modes of DMFC system and interfacing are done by using microcontroller. The power supply for tracking system is provide by an fuel cell stack module. It has simple structure with high efficiency.
\end{abstract}

Keywords: DMFC; portable power; wild life tracking; wireless sensor network; sensors.

\section{INTRODUCTION}

Rechargeable battery was the main power source of portable electronic devices such as cellular phones, notebooks, and PDA's. The battery has several limitations. External charging power is required and it has low power density. In proposed system we are having DMFC system, it has higher power density compared to rechargeable batteries. It has less operating temperature compared to other fuel cell. In several passive DMFC system have been proposed, passive DMFC system can be operated without the help of external devices. Fuel efficiency is low in passive DMFC system because too much heat is generated in its stack. An active DMFC system is more reliable and performs better than the passive DMFC system. Existing system rectifies the following concern 1 . Fuel efficiency and power density should be high; 2 . Output voltage should not fluctuate when load varies; 3 . Response should be fast; 4 . Power should be supplied to the output load during the start-up. But the complex system structure and controls can be disadvantage in active DMFC system. In proposed system the complexity of system is get reduced by reducing mechanical part in proposed system.
Now a days protection of animals from human beings and human beings from animals is a great challenge in many of forest areas. The technology of sensors, GPS and microcontroller creates tracking of animals in forest area to a great extent. For wireless sensor network zig-bee is used. In proposed system temperature sensor, humidity sensor and vibration sensor are used at each sensor nodes, microcontroller senses the parameter and transmit to the base station. Real time clock is used for synchronizing all the sensor nodes at certain interval to rise if the controller is in sleep mode. The tracking system with zig-bee wireless network provides standard protocol that creates the infrastructure required for sensor network application.A physical object equipped with a radio is Zigbee device.Three different types of layers are used in Zigbee device like PHY,MA, and network layers. These layers are used to create and maintain the communication network interconnection individual Zigbee device.The application layer informations are communicated between the devices through Application Support Sub layer(APS).It is the most sophisticated of the three types and requires the more memory and computing power; 2. The Full Function Device (FFD) supports all 802.15.4 functions. It can function as a network co-ordinator, additional memory and computing power make it ideal; 3 . The Reduction Function Device (RFD) carries functionality to lower cost and functionality.

Also the system is get charged by using the above mentioned active DMFC system. It has advantages with simple structure and high efficiency.

\section{HARDWARE CONFIGURATION}

The system hardware part includes power circuit to charge a battery and tracking module with sensor unit and central console unit. Power circuit supplies power to the components which are used in proposed system. Sensor unit senses the parameter and gives to the control unit. The control unit analyse the parameter and produce the remedial measures. The block diagram of proposed system shown in Fig.1.

\subsection{Fuel Cell Stack}

The fuel chemical energy is directly converted into electrical energy via electrochemical redox reactions. The anode electrode is fed with methanol from the reservoir, while the cathode electrode adsorbs atmospheric oxygen.

Anode : $\mathrm{CH} 3 \mathrm{OH}+\mathrm{H} 2 \mathrm{O} \rightarrow \mathrm{CO} 2+6 \mathrm{H}++6 \mathrm{e}-\mathrm{At}$ 
At anode side, for each mole of methanol, six moles of protons and electrons are produced by oxidation (methanol oxidation reaction)

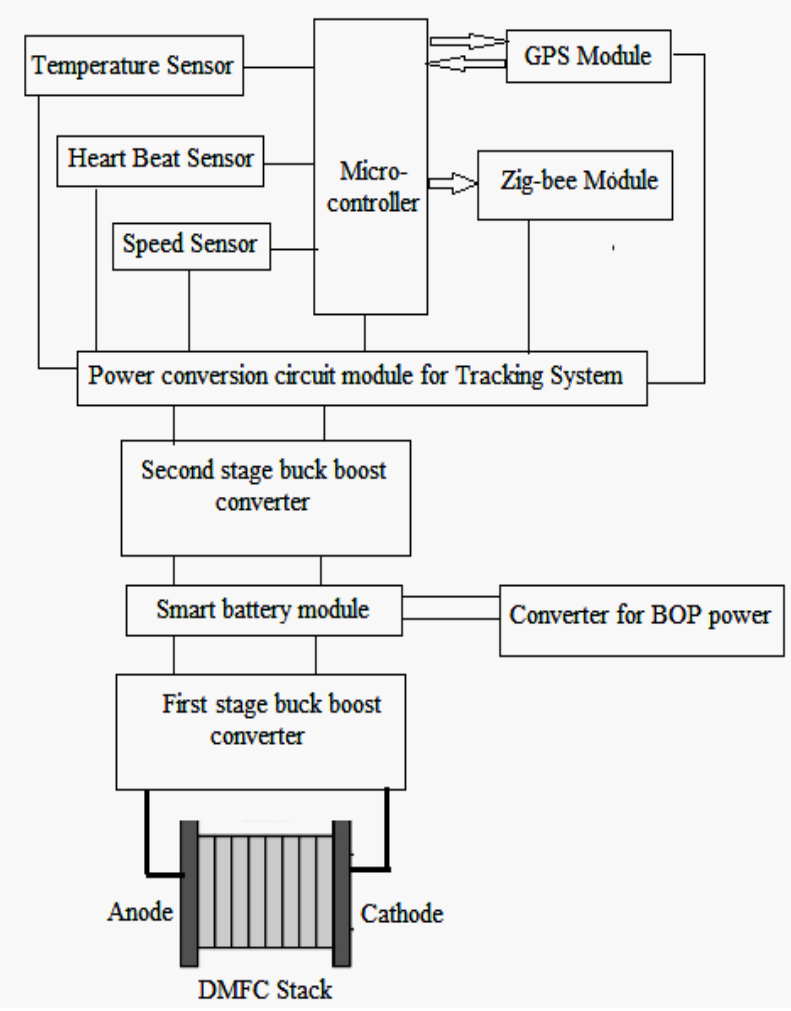

Fig. 1. Overall block Diagram of Proposed System

The six electrons are driven to the external circuit by a current collector, while the six protons flow through the membrane. Electrons from the external circuit and protons through the membrane merge at the cathode catalyst layer for participating to the oxygen-reduction reaction (ORR)

Cathode: $3 / 2 \mathrm{O} 2+6 \mathrm{H}++6 \mathrm{e}-\rightarrow 3 \mathrm{H} 2 \mathrm{O}$.

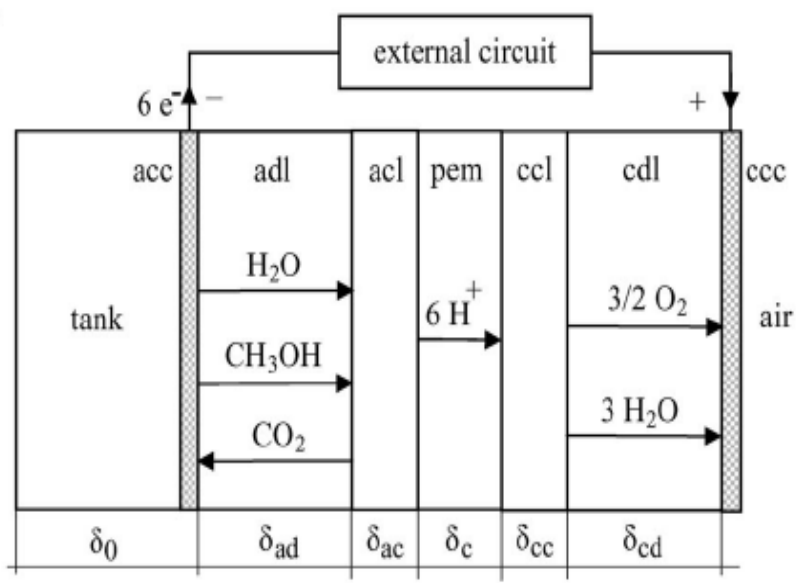

Fig. 2. Schematic diagram of a DMFC

The change in molar Gibbs free energy $\Delta g f$ for the reaction is $-698.2 \mathrm{~kJ} \cdot \mathrm{mol}-1$. Since six electrons are transferred for each molecule of methanol, the no-loss cell voltage Vno-loss cell is

$$
V_{\text {no-loss cell }}=\frac{\Delta \bar{g}_{f}}{6 F}=1.21 \mathrm{~V}
$$

where $F$ is the Faraday constant. The average cell voltage, however, is about $0.5 \mathrm{~V}$ due to a considerable voltage loss at the anode and the cathode.

\subsection{Mechanical System}

High fuel efficiency is essential for portable application power. Since the energy density of the pure methanol is 4.8 $\mathrm{Wh} / \mathrm{cm}^{3}$, fuel efficiency can be calculated as

$$
\text { Fuel efficiency }(\%)=\frac{\text { Power }(\mathrm{W}) \times \text { time }(\mathrm{h})}{\text { Fuel }\left(\mathrm{cm}^{3}\right) \times 4.8 \mathrm{Wh} / \mathrm{cm}^{3}}
$$

Mechanical part consists of mixer, fan and heat exchanger. Pure methanol, non reacted methanol and water are mixed in a mixer. By controlling the injection speed of the methanol, it controls the concentration of the methanol mixer. High fuel efficiency is needed for portable application. For that temperature must be controlled in DMFC stack. Stack temperature is controlled by fan and heat exchanger module. The second fan is used to controls the water level of the mixer by condensing the $\mathrm{H}_{2} \mathrm{O}$ vapour into water. The separator separates the liquids and gases like $\mathrm{H}_{2} \mathrm{O}$ vapour and $\mathrm{CO}_{2}$. The mechanical flow diagram is shown in Fig. 4.

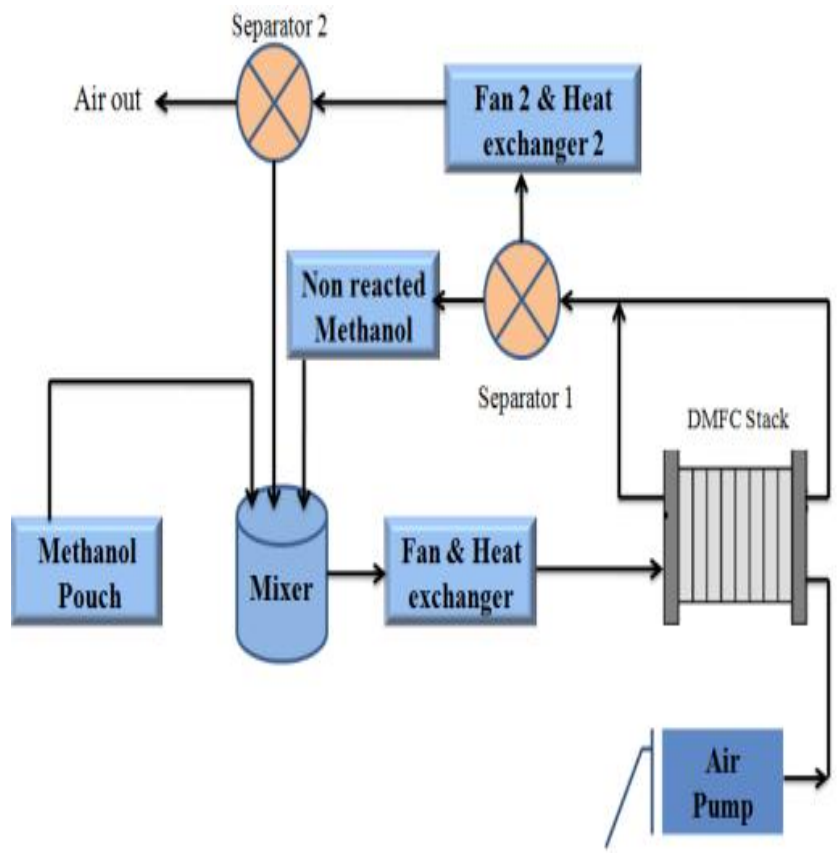

Fig. 3. Mechanical flow diagram

\subsection{Power Circuit}

The main power circuit of the DMFC system is shown in Fig. 5. This circuit is composed of two synchronous buck-boost converters. The first-stage converter charges the battery and/or supplies the power to the second-stage converter. The second stage converter regulates the output voltage. When diode rectifier is used the conduction loss will occur due to its voltage drop. To reduce this diode rectifier is replaced by 
synchronous rectifier using a low on-resistance MOSFET. In the continuous conduction mode of the converter, the voltage conversion ratio is

$$
\frac{V_{b}}{V_{\text {stack }}}=\frac{D}{1-D}
$$

where $V$ stack and $V b$ are the stack voltage and the battery voltage, respectively. This allows the battery voltage to be higher or lower than the fuel cell stack voltage based on the duty ratio $D$. When the battery voltage $V b$ is lower than the maximum battery voltage $V b$, max, the first-stage buck-boost converter is controlled by a current control loop and it maintains the constant stack current. On the contrary, when the battery voltage $V b$ is not lower than the maximum battery voltage $V b$, max, the first-stage buck-boost converter is controlled by a voltage control loop and it regulates the battery voltage $V b$. Therefore, the battery voltage $V b$ does not exceed the maximum battery voltage $V b$, max. The secondstage buck-boost converter is controlled by a voltage control loop and it regulates the output voltage. The second-stage converter is similar to the first-stage converter.

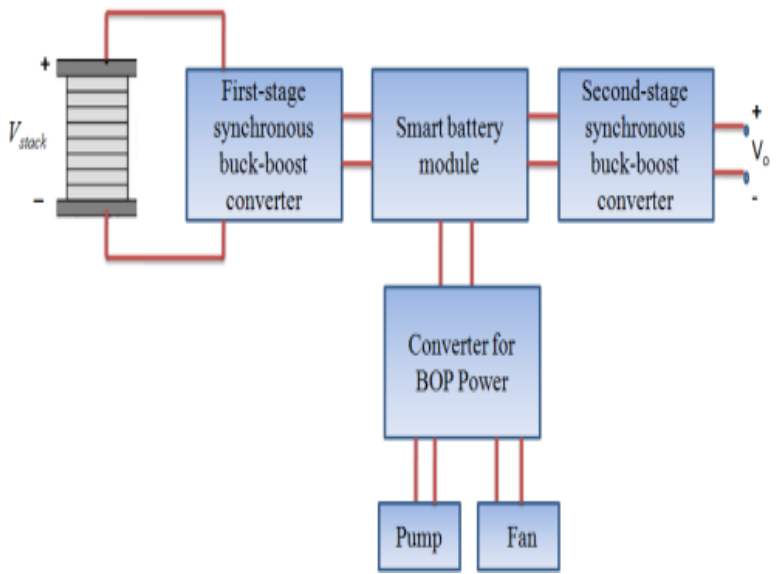

Fig. 4. Power flow diagram of DMFC Stack

The battery enables operating the BOP parts of the system and powers the output load during the start-up state. According to the load it will either absorb or supply the power. Also, it improves the system dynamic characteristics by providing or absorbing the power when the load varies. Furthermore, the battery can provide peak power at overload. If the battery is sufficiently charged, it can supply power to the load without generating power at the stack. The smart battery is composed of several battery cells and a battery management system (BMS). The BMS calculates the state-of-charge (SOC), balances cell voltage, and protects the battery from hazards.

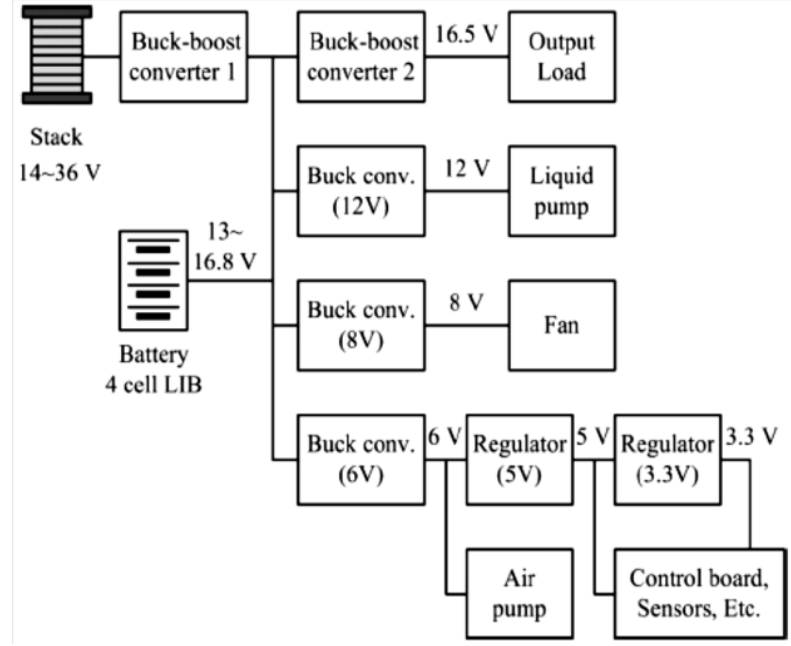

Fig. 5. Block diagram of power flow circuit

\section{4. $L M 35$}

\subsubsection{Precision Centigrade Temperature Sensors}

The LM35 series are precision integrated-circuit temperature sensors, whose output voltage is linearly proportional to the Celsius (Centigrade) temperature. The LM35 thus has an advantage over linear temperature sensors calibrated in ${ }^{\circ}$ Kelvin, as the user is not required to subtract a large constant voltage from its output to obtain convenient Centigrade scaling. The LM35 does not require any external calibration or trimming to provide typical accuracies of $\pm 1 / 4^{\circ} \mathrm{C}$ at room temperature and $\pm 3 / 4^{\circ} \mathrm{C}$ over a full -55 to $+150^{\circ} \mathrm{C}$ temperature range. Low cost is assured by trimming and calibration at the wafer level. The $\mathrm{LM}^{3} 5^{\text {ees }}$ low output impedance, linear output, and precise inherent calibration make interfacing to readout or control circuitry especially easy. It can be used with single power supplies, or with plus and minus supplies. As it draws only $60 \mu \mathrm{A}$ from its supply, it has very low self-heating, less than $0.1^{\circ} \mathrm{C}$ in still air. The $\mathrm{LM} 35$ is rated to operate over a $-55^{\circ}$ to $+150^{\circ} \mathrm{C}$ temperature range, while the $\mathrm{LM} 35 \mathrm{C}$ is rated for a $-40^{\circ}$ to $+110^{\circ} \mathrm{C}$ range $\left(-10^{\circ}\right.$ with improved accuracy). The LM35 series is available packaged in hermetic TO-46 transistor packages, while the LM35C, LM35CA, and LM35D are also available in the plastic TO-92 transistor package. The LM35D is also available in an 8-lead surface mount small outline package and a plastic TO-220 package. The LM35 can be applied easily in the same way as other integrated-circuit temperature sensors. Based on our convenience it may be glued on the surface. The temperature of the sensor should be in the range of $0.01{ }^{\circ} \mathrm{C}$ of surface temperature. This presumes that the ambient air temperature is almost the same as the surface temperature; if the air temperature were much higher or lower than the surface temperature, the actual temperature of the LM35 die would be at an intermediate temperature between the surface temperature and the air temperature. 


\subsubsection{Humidity sensor-PHILIPS HI}

It measures the electronic hygrometers for domestic use. This capacitive atmospheric humidity sensor consists of a nonconductive foil, which is covered on both sides with a layer of gold. The dielectric constant of the foil changes as a function of the relative humidity of the ambient atmosphere and, accordingly, the capacitance value of the sensor is a measure for relative humidity about animals.

\subsubsection{Accelerometer and passive infrared sensor}

Other types of sensors are also used such as accelerometer, passive infrared sensor which is used to predict the motion Pyroelectric devices, such as the PIR sensor, have elements made of a crystalline material that generates an electric charge when exposed to infrared radiation. The changes in the amount of infrared striking the element change the voltages generated, which are measured by an on-board amplifier. The device contains a special filter called a Fresnel lens, which focuses the infrared signals onto the element. As the ambient infrared signals change rapidly, the on-board amplifier trips the output to indicate motion. The PIR Passive Infra-Red) Sensor is a pyroelectric device that detects motion by measuring changes in the infrared (heat) levels emitted by surrounding objects. This motion can be detected by checking for a sudden change in the surrounding IR patterns. When motion is detected the PIR sensor outputs a high signal on its output pin. This logic signal can be read by a microcontroller or used to drive a transistor to switch a higher current load.

\subsubsection{Warm up time}

The PIR Sensor requires a ,warm-upe time in order to function properly. This is due to the settling time involved in „learninge its environment. This could be anywhere from 1-2 Minutes. After this warm up time, sensor will be ready to use.

With the help of all these sensors, the signals are sensed and is processed by the microcontroller based upon the threshold value. If the sensed value is greater than the threshold alarm will be raised and in the particular zone where the dangers occur.

\section{SOFTWARE DESCRIPTION}

\subsection{Software Control Module}

No need or very light load is connected, when fuel cells need a long start-up time to reach its optimal reaction condition. The generated power depends on the relationship among the stack current, the spent power by the BOP parts, and the chemical reaction condition.

The power relationship among them has an optimal operating condition that the fuel efficiency and the energy density are maximized. Therefore, the power should be generated at an optimal operating point to achieve high fuel efficiency and high energy density. To obtain the aforementioned optimization, four operating modes are defined and respective control algorithms are proposed for the DMFC-battery hybrid system. The diagram of the proposed system operation is shown in Fig. 6.

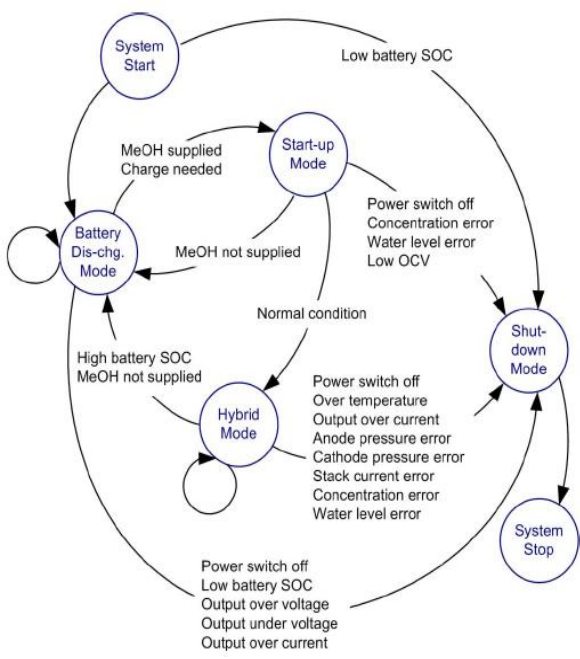

Fig. 6. System operation control diagram

\subsubsection{Battery Discharging Mode}

In the battery discharging mode, the first-stage converter and BOP parts are turned off. Only the battery provides the power to the load. This mode enables the power to be provided immediately when the system is turned on and prevents low efficiency caused by low power generation at the stack. When the battery SOC comes down under SOCL, this mode changes to the start-up mode.

\subsubsection{Start-up Mode}

In this mode, all of the sensor information are checked and BOP parts such as the motors and pumps are turned on sequentially for a stable operation. The methanol concentration is an important parameter that affects the performance of DMFC. While a low concentration of methanol mixture increases fuel efficiency, it can damage the DMFC stack. Therefore, the concentration should be controlled accurately before the air pump is turned on. The target concentration is given by the lookup table according to the outside temperature and the air pressure. The mixture concentration is controlled by supplying the methanol from the liquid pump 1.To supply precise amounts of methanol into the mixer, the flow rate of the liquid pump 1 is controlled by the PID controller. The open circuit voltage of the stack VOC is checked for the stack status. VOC should become higher than the minimum open circuit voltage VOC, min within few minutes. If the system suffers from short circuit, low stack performance, or no fuel supply, the open circuit voltage VOC is lower than the minimum open circuit voltage $V O C$, min. In this case, the operating mode is changed to the shut-down mode. On the other hand, if the open circuit voltage VOC is higher than the minimum open circuit voltage $V O C$, min and the water level is reasonable, the operating mode is changed to the hybrid mode since the DMFC stack can generate power stably.

\subsubsection{Hybrid Mode}

At the beginning of this mode, the stack current is increased from almost zero to the rated current in a few minutes. And then, the stack current is maintained constantly. The generated power is provided to the load and the battery is charged or discharged according to the load power. $P o$ is the output power, $P$ stack is the generated power of the stack, $P B O P$ is the power used in the BOP parts, $P b$,chg is the battery 
charging power, $\eta \mathrm{BBC} 1$ is the efficiency of the first-stage buck-boost converter, $\eta \mathrm{BBC} 2$ is the efficiency of the secondstage buck-boost converter, and $\eta \mathrm{BOP}$ is the efficiency of the BOP converters. In this mode, a stack temperature control, an air pump control, and a water level control are also required. As mentioned in Section II-B, the stack temperature is measured by the thermistor and is controlled by the injected mixture temperature, which is controlled by Fan 1with theHEX1. The water level is controlled by Fan 2 with the HEX 2. Fan 2 with the HEX 2 condenses water and the condensed water flows into the mixer. The target air flow rate of the air pump is selected by the lookup table data based on the outside air pressure. To complement the reduction in pump performance, all pump controllers are composed of PI controllers in closed loop. This mode is changed to battery discharging mode when the battery SOC becomes higher than $S O C h$, or this mode is changed to shut-down mode when the system suffers from high stack temperature, over-current, and the out of range air pressure and stack current.

\subsubsection{Shut-Down Mode}

All parts are shut down sequentially to remove the air in the anode of stack and the pipes connected to the anode. This mode reduces the chemical reaction when the DMFC system is shut down.

\subsection{Micro-controller configuration}

The AT89S52 is a low power, high performance CMOS 8-bit microcontroller with 8 Kbytes of in-system programmable Flash memory. The device is manufactured using Atmel's high-density non-volatile memory technology and is compatible with the industry standard 80C51 instruction set and pinout. The on-chip Flash allows the program memory to be reprogrammed in-system or by a conventional non-volatile memory programmer.

By combing a versatile 8-bit CPU with in-system programmable Flash on a monolithic chip, the Atmel AT89S52 is a powerful microcontroller which provides a highly flexible and cost effective solution to many embedded control applications.

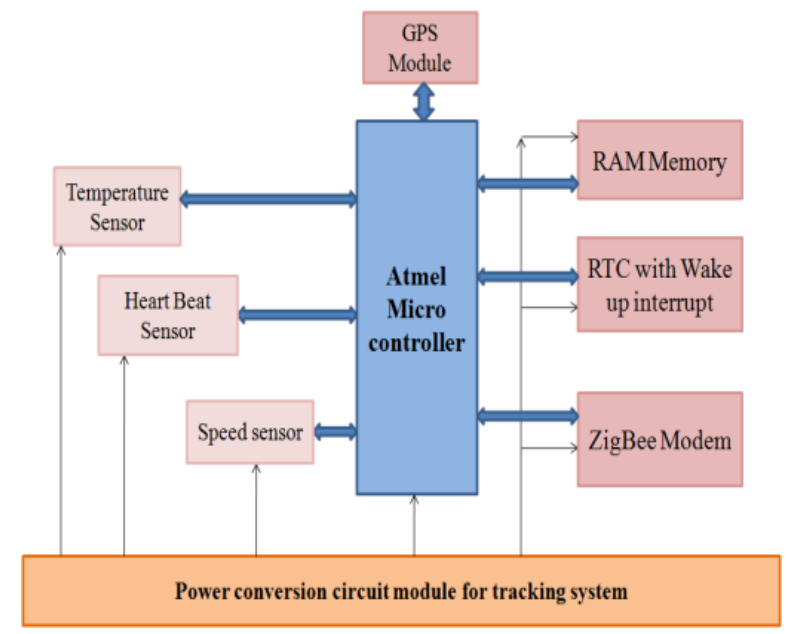

Fig. 7. Block diagram of tracking module

The AT89S52 provides the following standard features: 8 Kbytes of Flash, 256 bytes of RAM, 32 I/O lines, watchdog timer, two data pointers, three 16-bit timer/counters, a six- vector two level interrupt architecture, a full duplex serial port, on-chip oscillator and clock circuitry. In addition, the AT89S52 is designed with static logic for operation down to zero frequency and supports two software selectable power saving modes. The Idle mode stops the CPU while allowing the RAM, timer/ counters, serial port and interrupt system to continue functioning. The power down mode saves the RAM contests but freezes the oscillator, disabling all other chip functions until the next interrupt or hardware reset.

\section{CONCLUSION}

From the technology used in proposed system is able to track animal's current situation. Also we can avoid threatening of human beings by animals and vice- versa. Here we are going to measure heart rate, temperature, motion xaused by things nearby by using infrared sensor and humidity of an animal. It ensures high flexibility and high performance is obtained. An active DMFC system is used for give a supply for tracking system. By using a battery module, the DMFC system can provide power during animal tracking. By using the algorithms and operation modes enables the DMFC to generate power at an optimal operating condition and achieve high fuel efficiency and high energy density.

\section{REFERENCES}

[1] L. Palma and P. N. Enjeti, "A modular fuel cell, modular DC-DC converter concept for high performance and enhanced reliability," IEEE Trans.Power Electron., vol. 24, no. 6, pp. 1437-1443, Aug. 2009.

[2] K. Jin, X. Ruan, M. Yang, and M. Xu, "Power management for fuel-cell power system cold start," IEEE Trans. Power Electron., vol. 24, no. 10,pp. 2391-2395, Oct. 2009.

[3] J. M. Kwon, E. H. Kim, B. H. Kwon, and K. H. Nam, "High-efficiency fuel cell power conditioning system with input current ripple reduction," in IEEE Trans. Ind. Electron., vol. 56, no. 3, pp. 826-834, Mar. 2009.

[4] J. M. Kwon and B. H. Kwon, "High step-up active-clamp converter with input-current doubler and output-voltage doubler for fuel cell power systems," IEEE Trans. Power Electron., vol. 24, no. 1, pp. 108-115, Jan.2009.

[5] C. K. Dyer, "Fuel cells for portable applications," $J$. Power Source, vol. 106, no. 1, pp. 31-34, Apr. 2002.

[6] R. Rashidi, I. Dincer, G. F. Naterer, and P. Berg, "Performance evaluation of direct methanol fuel cells for portable applications," J. Power Source, vol. 187, no. 2, pp. 509-516, Feb. 2009.

[7] A. Gebregergis, P. Pillay, D. Bhattacharyya, and R. Rengaswemy, "Solid oxide fuel cell modeling," IEEE Trans. Ind. Electron., vol. 56, no. 1,pp. 139-148, Jan. 2009.

[8] S. K. Kamarudin, F. Achmad, and W. R. W. Daud, "Overview on the application of direct methanol fuel cell (DMFC) for portable electronic devices," Int. J. Hydrogen Energy, vol. 34, no. 16, pp. 6902-6916, Aug.2009.

[9] L. Zhong, X. Wang, Y. Jiang, Q. Zhang, X. Qiu, Y. Zhou, and L. Liu, "A micro-direct methanol fuel cell stack with optimized design and microfabrication," $J$. Power Source, vol. 143, no. 1, pp. 70-76, May 2008. 
[10] N. Paust, S. Krumbholz, S. Munt, C. Miller, R. Zengerle, C. Ziegler, and P. Koltay, "Design of a passive and portable DMFC operating in all orientations," in Proc. IEEE -Microelectromechan. Syst. (MEMS), Jan. 2009, pp. 1091-1094.

[11] P. Alotto, M. Guarnieri, and F. Moro, "Optimal design of micro direct methanol fuel cells for low-power applications," IEEE Trans. Magn.,vol. 45, no. 3, pp. 1570-1573, Mar. 2009

[12] B. Sahu and Gabriel A. Rinc'on-Mora, "A low voltage, dynamic, noninverting, synchronous buck-boost converter for portable applications," IEEE Trans. Power Electron., vol. 19, no. 2, pp. 443-452, Mar. 2004.

[13] J. J. Lee, J. M. Kwon, E. H. Kim, W. Y. Choi, and B. H. Kwon, "Singlestage single-switch PFC flyback converter using a synchronous rectifier," IEEE Trans. Ind. Electron., vol. 55, no. 3, pp. 1352-1365, Mar. 2008.

[14] C. Blake, D. Kinzer, and P.Wood, "Synchronous rectifiers versus Schottky diodes: A comparison of the losses of a synchronous rectifier versus the losses of a Schottky diode rectifier," in Proc. IEEE Appl. Power Electron.Conf., Feb., 1994, vol. 1, pp. 17-23.
[15] W. Jiang and B. Fahimi, "Active current sharing and source management in fuel cell-battery hybrid power system," IEEE Trans. Ind. Electron., vol. 57, no. 2, pp. 752-761, Feb. 2010.

[16] C. A. Ramos-Paja, C. Bordons, A. Romero, R. Giral, and L. Mart'ınez-Salamero, "Minimum fuel consumption strategy for PEM fuel cells," IEEE Trans. Ind. Electron. vol. 56, no. 3, pp. 685-696, Mar. 2009.

[17] A. Kundu, J. H. Jang, J. H. Gil, C. R. Jung, H. R. Lee, S.H. Kim, B. Ku, and Y. S. Oh, "Micro-fuel cells-Current development and applications," J. Power Sources, vol. 170, no. 1, pp. 67-78, Jun. 2007.

[18] K. Scott, P. Argyropoulos, and K. Sundmacher, "A model for the liquid feed direct methanol fuel cell," $J$. Elect Chem., vol. 477, no. 2, pp. 97-110, Nov. 1999.

[19] "ZigBee Wireless Network to Transfer Water-Sludge interface Data""- by 2Sun Jinsheng, 2Wang Ning and 2Liu Liping August 20 - 23, 2006, 